\title{
Video Article \\ Bronchoalveolar Lavage of Murine Lungs to Analyze Inflammatory Cell Infiltration
}

\author{
Lien Van Hoecke ${ }^{1,2}$, Emma Richelle Job ${ }^{1,2}$, Xavier Saelens ${ }^{1,2}$, Kenny Roose ${ }^{1,2}$ \\ ${ }^{1}$ UGent Center for Medical Biotechnology, VIB \\ ${ }^{2}$ Department of Biomedical Molecular Biology, Ghent University (UGent)
}

Correspondence to: Lien Van Hoecke at lien.vanhoecke@vib-ugent.be

URL: https://www.jove.com/video/55398

DOI: doi:10.3791/55398

Keywords: Immunology, Issue 123, lung, immune cells, bronchoalveolar lavage (BAL), lymphocytes, macrophages, cell differential count, flow cytometry

Date Published: 5/4/2017

Citation: Van Hoecke, L., Job, E.R., Saelens, X., Roose, K. Bronchoalveolar Lavage of Murine Lungs to Analyze Inflammatory Cell Infiltration. J. Vis. Exp. (123), e55398, doi:10.3791/55398 (2017).

\section{Abstract}

Bronchoalveolar Lavage (BAL) is an experimental procedure that is used to examine the cellular and acellular content of the lung lumen ex vivo to gain insight into an ongoing disease state.

Here, a simple and efficient method is described to perform BAL on murine lungs without the need of special tools or equipment. BAL fluid is isolated by inserting a catheter in the trachea of terminally anesthetized mice, through which a saline solution is instilled into the bronchioles. The instilled fluid is gently retracted to maximize BAL fluid retrieval and to minimize shearing forces. This technique allows the viability, function, and structure of cells within the airways and BAL fluid to be preserved.

Numerous techniques may be applied to gain further understanding of the disease state of the lung. Here, a commonly used technique for the identification and enumeration of different types of immune cells is described, where flow cytometry is combined with a select panel of fluorescently labeled cell surface-specific markers. The BAL procedure presented here can also be used to analyze infectious agents, fluid constituents, or inhaled particles within murine lungs.

\section{Video Link}

The video component of this article can be found at https://www.jove.com/video/55398/

\section{Introduction}

The airways encounter numerous insults, which can lead to inflammation, pathogen invasion, or malignant transformation. The epithelial cells that line the lung lumen form one of the major barriers of the mammalian body. Together with alveolar macrophages, they prevent environmental threats from gaining entry to the systemic system via the airways. Examples of such threats include organic and inorganic chemicals, bacteria, and viruses. Likewise, specific immunizations or therapeutic interventions can be designed to target the lungs. In all these instances, an elaborate analysis of the evoked response is important to understand, intervene, or prevent biological processes that take place within the respiratory system.

Bronchoalveolar lavage (BAL) is an invaluable method to analyze such responses, as the resulting samples contain important information about the inflammatory responses, immune mechanisms, and infectious disease progression that can occur in the pulmonary airways ${ }^{1,2}$. By using BAL, it is possible to study the infiltrating cells. This contrasts with digested lungs, that give a "dirtier" cell population, with many dead and sticky cells. BAL is performed by introducing a saline solution into the terminal bronchioles and subsequently recovering this solution. The retrieved solution can then be used to quantify and phenotypically analyze resident lung and infiltrating inflammatory cells. This method is frequently applied to study cellular influx in disease models of the airways, such as asthma, Chronic Obstructive Pulmonary Disease (COPD), and infectious disease models. Apart from the cellular composition, the molecular composition of the pulmonary airways is also reflected in the BAL fluid. To analyze this, Enzyme-linked Immunosorbent Assay (ELISA), immunoblot, and the simultaneous analysis of multiple cytokines by a cytokine bead array can be performed to assess the presence of cytokines and chemokines.

BAL is a well-established method to study the influx of inflammatory cells in inflammatory respiratory disease animal models. The observation of an altered cellular influx (e.g., increased levels of lymphocytes, eosinophils, or neutrophils) can lead to better insights into the disease and can be an objective parameter to assess the performance of a therapeutic intervention.

The accurate and reproducible interpretation of BAL cellular analysis requires that the BAL is performed correctly and that the collected fluid is handled and processed properly. The term "bronchial lavage" was introduced more than eighty years ago by Stitt ${ }^{3}$. In 1961 , Myrvik obtained alveolar macrophages from the lavage fluid of rabbit lungs ${ }^{3}$. BAL is now a commonly used method to analyze and monitor the lungs in the mouse model, yet there is still no report of a standardized BAL procedure in the scientific literature ${ }^{4,5}$. Furthermore, there are probably as many ways 
to perform BAL as there are research laboratories using the technique $\mathrm{e}^{3,6,7,8,9,10,11}$. It is important that the data obtained from the BAL represent the whole murine lung, and not only a part of the lung. This kind of variability complicates the interpretation and comparison of results between different trials.

Here, a basic, inexpensive, and reproducible BAL procedure is described that allows the collection of the cellular and soluble fraction present in the airway lumen of the mouse. In short, a catheter is placed into the exposed trachea of a terminally anesthetized mouse. A syringe is connected to the catheter, and a buffered saline solution containing ethylenediaminetetraacetic acid (EDTA) is introduced into the lungs. The lung lumen is sampled by gentle repeated flushing of the saline solution using the plunger. The negative pressure applied during this step is minimal to prevent airway collapse. Following collection, the obtained BAL should be processed further to enumerate and identify the cells by flow cytometry.

\section{Protocol}

All animal experiments described in this study were conducted according to the national (Belgian Law 14/08/1986 and 22/12/2003, Belgian Royal Decree 06/04/2010) and European legislation (EU Directives 2010/63/EU and 86/609/EEC). All experiments on mice and all animal protocols were approved by the ethics committee of Ghent University (permit numbers LA1400091 and EC2016-027).

\section{Preparation}

1. Lavage fluid

1. Prepare a balanced salt solution with $100 \mu \mathrm{M}$ ethylenediaminetetraacetic acid (EDTA).

NOTE: To measure protein levels in the BAL fluid, it is recommended to add protease inhibitors to prevent protease activity in the BAL fluid.

2. Catheter

1. Make a catheter by inserting a $23 \mathrm{G}$ needle into transparent plastic polyethylene $21 \mathrm{G}$ tubing (inner diameter: $0.58 \mathrm{~mm}$, outer diameter: $0.965 \mathrm{~mm}$, and length: $0.5 \mathrm{~cm}$ ). Premade catheters can also be used.

3. Anesthetics

1. Prepare a terminal anesthetic, preferably one that causes respiratory arrest (e.g., a barbiturate like sodium pentobarbital (>100 mg/kg) solution in phosphate-buffered saline (PBS)).

NOTE: It is recommended to use injected anesthesia instead of inhaled anesthesia, as inhaled anesthesia may have an influence on the BAL fluid content. $\mathrm{CO}_{2}$, for example has an influence on the $\mathrm{pH}$ of the blood and consequently on the redistribution of different compounds ${ }^{12}$.

4. Ammonium-chloride-potassium (ACK) red blood cell lysis buffer

1. Prepare an ACK lysis buffer by dissolving $8.29 \mathrm{~g}$ of $\mathrm{NH}_{4} \mathrm{Cl}$ and $1 \mathrm{~g}$ of $\mathrm{KHCO}_{3}$ in $1 \mathrm{~L}$ of $\mathrm{H}_{2} \mathrm{O}$ with $100 \mu \mathrm{M}$ EDTA; red blood cell lysis buffer can also be purchased from an external source.

\section{Performing the Bronchoalveolar Lavage (BAL)}

1. Introducing the catheter into the trachea

1. Euthanize the mouse by intraperitoneal injection of a lethal dose of a short-acting barbiturate anesthetic using a $26 \mathrm{G}$ needle. To confirm proper lethal anesthetization, pinch the rear paw of the mouse with forceps to check the foot reflex.

2. Place the animal on its back on a surgical plate and fix the mouse by pinning down the limbs.

3. Spray $70 \%$ ethanol on the neck to disinfect. Make an incision in the neck skin near the trachea using a scalpel.

4. Open the skin to expose the salivary glands. Separate the salivary glands by using pincers to expose the sternohyoid muscle. Incise the muscle around the trachea using pincers to expose the trachea.

5. Place a cotton thread under the trachea using pincers.

6. Carefully puncture the middle of the exposed trachea between two cartilage rings with a $26 \mathrm{G}$ needle. Take care not to damage the trachea any further.

7. Insert the catheter about $0.5 \mathrm{~cm}$ into the trachea. Ensure that the catheter is not inserted too far down into the trachea, as this can lead to damage of the lung structure.

8. Stabilize the catheter by tying the trachea around the catheter using the cotton thread placed in step 2.1.5. If the catheter is not tied sufficiently, the injected balanced salt solution may flow towards the upper part of the respiratory tract instead of down into the lungs.

2. Collect the lavage fluid

1. Load a $1 \mathrm{~mL}$ syringe with $1 \mathrm{~mL}$ of sterile balanced salt solution with $100 \mu \mathrm{M}$ EDTA.

2. Connect the $1 \mathrm{~mL}$ syringe to the catheter and gently inject the salt/EDTA solution into the lung.

3. Aspirate the solution gently while massaging the thorax of the mouse. If the aspirate fluid is not visible in the syringe, carefully insert the catheter a little further down or up the trachea.

4. Remove the syringe from the needle and transfer the recovered lavage fluid into a $15 \mathrm{~mL}$ tube placed on ice. Normally, $700-900 \mu \mathrm{L}$ of BAL is recovered from $1 \mathrm{~mL}$ of injected solution.

5. Repeat steps 2.2.1 - 2.2.4 twice more.

NOTE: If the purpose is to analyze the non-cellular content, it is recommended to concentrate the pooled samples when there are issues with sensitivity. 


\section{Collecting the Cellular and Noncellular Components of the BAL Fluid}

1. Centrifuge the lavage fluid for $7 \mathrm{~min}$ at $400 \mathrm{xg}$ and $4{ }^{\circ} \mathrm{C}$.

2. Collect the supernatant and immediately use it for further analysis (e.g., ELISA) or freeze at $-80^{\circ} \mathrm{C}$. Keep the cell pellet to analyze the cellular influx in the lungs.

3. Resuspend the cell pellet in $200 \mu \mathrm{L}$ of ACK lysing buffer.

NOTE: This step ensures the lysis of the erythrocytes while keeping the white blood cells intact.

4. Incubate for 2 min at RT.

NOTE: To reduce the variation caused by red cell lysis, this step should not be performed for longer than 2 min.

5. Add $1 \mathrm{~mL}$ of cold PBS to dilute the ACK lysing buffer.

6. Centrifuge for $7 \mathrm{~min}$ at $400 \mathrm{xg}$ and $4{ }^{\circ} \mathrm{C}$. Discard the supernatant and re-suspend the cells in an adequate volume of PBS for downstream analysis (see below). NOTE: The volume of the PBS depends on the downstream study that will be performed.

\section{Analysis of the Different Cell Types in the BAL Fluid by Flow Cytometry}

NOTE: One possibility is to analyze the absolute and relative cellular composition of the BAL fluid by performing flow cytometry. The goal of this paper is to elaborate the technique of BAL. Flow cytometry is a specialized technique on its own. It is recommended to read specialized papers on the flow cytometry technique ${ }^{13,14,15,16,17}$. Antibodies coupled to a fluorophore that recognize surface antigens (see Table 1) specific to a particular cell type(s) are used. By using a gating strategy, it is possible to identify T cells, macrophages, dendritic cells, B cells, eosinophils, and neutrophils in the cell fraction of the BAL.

\begin{tabular}{|l|l|}
\hline Antigen & Cell type \\
\hline Cluster of differentiation 3 (CD3) & Expressed on T cells \\
\hline Cluster of differentiation 11c (CD11c) & $\begin{array}{l}\text { High expression on most dendritic cells, but also on monocytes, } \\
\text { macrophages, neutrophils, and some B cells. }\end{array}$ \\
\hline Cluster of differentiation 11b (CD11b) & $\begin{array}{l}\text { Expressed on the surface of many leukocytes including monocytes, } \\
\text { neutrophils, natural killer cells, granulocytes and macrophages. }\end{array}$ \\
\hline SiglecF & Alveolar macrophages and eosinophils. \\
\hline MHCII & $\begin{array}{l}\text { Normally found only on antigen-presenting cells such as dendritic cells, } \\
\text { mononuclear phagocytes and B-cells. }\end{array}$ \\
\hline CD19 & B-lymphocyte antigen \\
\hline Ly-6G & A marker for monocytes, granulocytes and neutrophils \\
\hline
\end{tabular}

Table 1: Selection of Immune Cell Surface Antigens. This table provides a list of surface epitopes used to characterize the different cell types.

Combinations of several markers will be required to reliably define a specific cell type. 


\begin{tabular}{|c|c|c|c|c|}
\hline Samples & & & & \\
\hline \multirow[t]{4}{*}{ Tube } & $\begin{array}{l}\text { Antigen-fluorophore to be } \\
\text { added to cells }\end{array}$ & $\begin{array}{l}\text { Antibody stock } \\
\text { concentration }(\mathrm{mg} / \mathrm{mL})\end{array}$ & Antibody dilution & Total volume $(\mu \mathrm{L})$ \\
\hline & Fixable viability dye & 0.2 & $1 / 1000$ & 50 \\
\hline & CD11c & 0.2 & $1 / 800$ & 50 \\
\hline & SiglecF & 0.2 & $1 / 100$ & 50 \\
\hline \multirow[t]{5}{*}{ sample X } & $\mathrm{MHCll}$ & 0.2 & $1 / 200$ & 50 \\
\hline & CD3 & 0.2 & $1 / 200$ & 50 \\
\hline & CD19 & 0.2 & $1 / 200$ & 50 \\
\hline & CD11b & 0.2 & $1 / 200$ & 50 \\
\hline & Ly6G & 0.2 & $1 / 200$ & 50 \\
\hline \multicolumn{5}{|l|}{ Voltage controls } \\
\hline Tube & $\begin{array}{l}\text { Antigen-fluorophore to be } \\
\text { added to cells }\end{array}$ & \begin{tabular}{|l} 
Antibody stock \\
concentration $(\mathrm{mg} / \mathrm{mL})$
\end{tabular} & Antibody dilution & Total volume $(\mu \mathrm{L})$ \\
\hline Unstained cells & 1 & 1 & I & 50 \\
\hline Single stained cells & Fixable viability dye & 0.2 & $1 / 1000$ & 50 \\
\hline Single stained cells & CD11c & 0.2 & $1 / 800$ & 50 \\
\hline Single stained cells & SiglecF & 0.2 & $1 / 100$ & 50 \\
\hline Single stained cells & MHCII & 0.2 & $1 / 200$ & 50 \\
\hline Single stained cells & CD3 & 0.2 & $1 / 200$ & 50 \\
\hline Single stained cells & CD19 & 0.2 & $1 / 200$ & 50 \\
\hline Single stained cells & CD11b & 0.2 & $1 / 200$ & 50 \\
\hline Single stained cells & Ly6G & 0.2 & $1 / 200$ & 50 \\
\hline \multicolumn{5}{|c|}{ Compensation controls } \\
\hline Tube & $\begin{array}{l}\text { Antigen-fluorophore to be } \\
\text { added to beads }\end{array}$ & $\begin{array}{l}\text { Antibody stock } \\
\text { concentration }(\mathrm{mg} / \mathrm{mL})\end{array}$ & Antibody dilution & Total volume $(\mu \mathrm{L})$ \\
\hline Unstained beads & 1 & 1 & 1 & 200 \\
\hline Single stained beads & CD11c & 0.2 & $1 / 2000$ & 200 \\
\hline Single stained beads & SiglecF & 0.2 & $1 / 2000$ & 200 \\
\hline Single stained beads & $\mathrm{MHCll}$ & 0.2 & $1 / 200$ & 200 \\
\hline Single stained beads & CD3 & 0.2 & $1 / 2000$ & 200 \\
\hline Single stained beads & CD19 & 0.2 & $1 / 2000$ & 200 \\
\hline Single stained beads & CD11b & 0.2 & $1 / 400$ & 200 \\
\hline Single stained beads & Ly6G & 0.2 & $1 / 200$ & 200 \\
\hline
\end{tabular}

Table 2. List of Controls to be Included. This table shows all necessary controls for the accurate interpretation of the obtained results.

1. Cell surface staining

NOTE: It is important to include all the critical controls for the flow cytometry analysis. Three sets of tubes are needed (see Table 2): (1) tubes containing the samples; (2) tubes with BAL cells for each antibody-fluorophore to make single stains; this allows for the determination of the voltages for each channel on the flow cytometer; and (3) tubes with beads for each antibody-fluorophore to make single stains; this is to determine the compensation matrix.

1. Make a mix of the antibodies and Fc-block (anti-CD16/CD32) in PBS at the appropriate dilutions (see Table 2). It is necessary to determine the optimal working dilution for each antibody prior to the experiment.

2. Resuspend the cells in $50 \mu \mathrm{L}$ of the antibody mix for the sample and add $50 \mu \mathrm{L}$ of the appropriately diluted antibody to the critical controls.

NOTE: The staining can be performed in a 96-well, u-shaped plate. This makes it possible to easily reduce the stain volume and run significant amounts of samples.

3. Incubate for $30 \mathrm{~min}$ in the dark at $4{ }^{\circ} \mathrm{C}$

4. Centrifuge for $7 \mathrm{~min}$ at $400 \times \mathrm{g}$ and $4^{\circ} \mathrm{C}$. Discard the supernatant.

5. Re-suspend the cells in PBS to a final volume of $200 \mu \mathrm{L}$.

NOTE: This final volume depends on the minimal volume the flow cytometer can access. This can differ slightly between machines. In addition, the read volume depends on the number of cells and/or time the sample will take to run in the flow cytometer.

6. Use the samples and controls for flow cytometric analysis. 
NOTE: To determine the absolute cell number of the different cell populations, counting beads should be added. Add the same number of beads ( $\pm 25,000$ beads) to each sample just before measurement. By using forward and side scatter, counting beads can be identified by flow cytometry (see Figure 1). Subsequently, the absolute number of cells in the sample can be calculated by comparing the ratio of bead events to cell events. The following formula can be used:

absolute number of cells $=\frac{\text { added beads to the sample }}{\text { counted beads on flow cytometer }} \mathrm{X}$ counted number of cells

2. Flow cytometric analysis

NOTE: The flow cytometric analysis should be done immediately after the completion of the staining protocol. A flow cytometer with appropriate lasers and filters for signal detection must be used. Table 3 gives an overview of the lasers and filters needed for the study described in this manuscript. For more information on flow cytometric analysis, see Adan et al. ${ }^{18}$.

1. Set up the primary gates based on the forward and side scatter, excluding debris and doublets (see Figure 1).

2. Adjust the voltage and the compensation for spectral overlap with the help of the single-stained cells and beads.

NOTE: These settings are different for each flow cytometer and need be checked before every experiment. For correct flow analysis, the forward- and side-scatter voltages are critical. A correct forward and side scatter can help in the identification and the confirmation of the identity of the analyzed cells. To determine these voltages, an unstained sample should be run first.

3. Set up fluorescence gates for the surface antigen (see Figure 1) and analyze the samples.

\begin{tabular}{|l|l|l|}
\hline Laser type & Filter setup & \\
\hline & 505 LP & $525 / 50$ \\
\hline Blue $(488 \mathrm{~nm})$ & 550 LP & $575 / 26$ \\
\hline $100 \mathrm{~mW}$ & 670 LP & $685 / 35$ \\
\hline & 750 LP & $780 / 60$ \\
\hline violet $405 \mathrm{~nm}$ & & $450 / 50$ \\
\hline $100 \mathrm{~mW}$ & & \\
\hline red $633 \mathrm{~nm}$ & & $660 / 20$ \\
\hline $70 \mathrm{~mW}$ & $750 \mathrm{LP}$ & $780 / 60$ \\
\hline
\end{tabular}

Table 3: Overview of the Lasers and Filters of the Flow Cytometer used in This Study.

\section{Representative Results}

After performing BAL with $3 \times 1 \mathrm{~mL}$ of buffered salt solution, a volume between 2 and $3 \mathrm{~mL}$ should be recovered. This BAL fluid can be analyzed further to characterize the cellular and noncellular content. To investigate the presence of cytokines and chemokines, ELISA ${ }^{19}$, immunoblot ${ }^{20}$, and the simultaneous analysis of multiple cytokines by a cytokine bead array ${ }^{21}$ can be performed. In addition, the albumin and total protein content of this fluid can be determined 22 .

As an example, this manuscript describes how to analyze the cellular content of the BAL fluid by flow cytometry. The analyzed BAL fluid was collected from female Balb/cAnNCrl mice (age: 7 weeks) $24 \mathrm{~h}$ after they were intratracheally instilled with lipopolysaccharide. The following antibodies, coupled to a fluorophore, were used to identify the different cell types: CD11c, SiglecF, MHCII, CD3ع, CD19, Ly6g, and CD11b (see Table 1 and the Table of Materials). The fixable viability dye was also used. By using a gating strategy based on the differential expression of antigens on the surfaces of the different cell populations (Figure 1), it was possible to identify macrophages, dendritic cells, B cells, T cells, neutrophils, and eosinophils.

First, debris and doublets were gated out based on forward- and side-scatter parameters. A viability dye facilitated gating on the live cells. Next, CD11c high cells and CD11c low cells were identified. In the CD11c high population, macrophages and dendritic cells were identified based

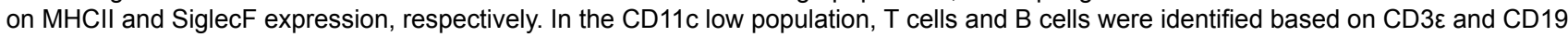
expression, respectively. In the remaining cell population, neutrophils and eosinophils were identified based on the CD11b and Ly-6G marker expression, respectively.

Counting beads were added to determine the absolute cell numbers of the different cell populations by comparing the ratio of bead events to cell events $^{23}$. These counting beads were identified based on their forward- and side-scatter properties (Figure 1). Table 4 gives an overview of the absolute cell numbers of the different cell populations in the BAL fluid of a naïve mouse and a mouse that was stimulated for $24 \mathrm{~h}$ with $5 \mu \mathrm{g}$ of lipopolysaccharide. 


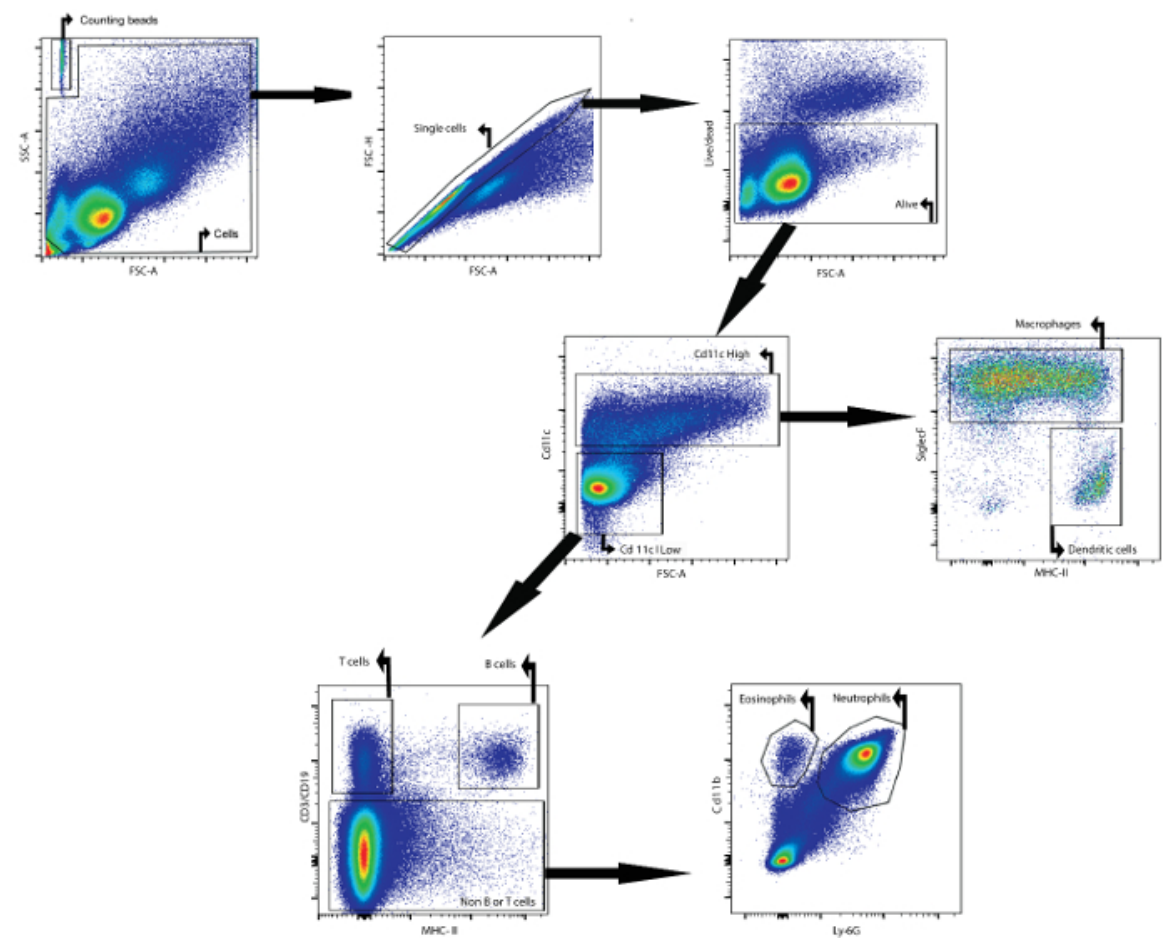

Figure 1: Gating Strategy for the Flow Cytometric Detection of Macrophages, Dendritic Cells, T Cells, B Cells, Neutrophils, and Eosinophils in BAL Fluid. BAL cells were isolated using the described BAL protocol. Cells were isolated from mice $24 \mathrm{~h}$ after intratracheal instillation of lipopolysaccharide. Counting beads and cells were identified based on forward- and side-scatter properties. In the cell gate, single cells were identified using forward and side scatter. In this last population, cells that were alive were identified. CD11 $c^{\text {high }}$ cells and CD11c ${ }^{\text {low }}$ cells were then identified. In the CD11 $\mathrm{c}^{\text {high }}$ population, macrophages and dendritic cells were identified based on MHCII and SiglecF expression, respectively. In the CD11 $c^{\text {low }}$ population, $T$ cells and B cells were identified based on CD3E and CD19 expression, respectively. In the remaining cell population, neutrophils and eosinophils were identified based on CD11b and Ly-6G expression, respectively. Please click here to view a larger version of this figure.

\begin{tabular}{|l|l|l|}
\hline cell population & absolute number of cells in naive mice & $\begin{array}{l}\text { absolute number of cells in LPS stimulated } \\
\text { mice }\end{array}$ \\
\hline macrophages & 79,612 & 25,439 \\
\hline dendritic cells & 495 & 671 \\
\hline T cells & 45,271 & 28,089 \\
\hline B cells & 4,164 & 2,926 \\
\hline neutrophils & 632 & 566,716 \\
\hline eosinophils & 3,483 & 4,332 \\
\hline
\end{tabular}

Table 4: Representative Results of the Flow Cytometry Analysis on the BAL Fluid of Naïve and LPS-stimulated Mice.

\section{Discussion}

BAL is a useful technique to obtain cytological and biochemical information in response to infections or drugs. Initially, BAL was used to manage the excessive mucus production in human patients suffering from phosgene toxicity ${ }^{3}$. Nowadays, the technique is used in humans to investigate lung pathogenesis, diagnosis, and therapeutic management of diseases ${ }^{3,24}$. In laboratory animals, BAL is commonly used to monitor inflammatory responses, immune mechanisms, and infectious disease processes that occur in the pulmonary airways ${ }^{1,2}$.

To study the inflammatory cellular pattern in respiratory disease models, BAL should be followed by absolute and differential cell counting. In addition to the absolute cell number, the relative cell numbers are also of interest. For example, repair and cancer models show very small to no BAL cell count increases. In this model, the assessment of cellular composition is useful. By using cell staining combined with light microscopy, different cell types, such as eosinophils, neutrophils, macrophages, and lymphocytes, can be identified based on morphology ${ }^{25,26,27,28,29,30}$. Flow cytometry can be used for specific assessments, such as to identify different T-cell phenotypes ${ }^{7,31}$. In addition to the identification of the different infiltrating cell populations, the non-cellular composition of the lung can be investigated using BAL. Methods such as ELISA, immunoblot, cytokine bead array, immunohistochemistry, and quantitative polymerase chain reaction are performed on BAL fluid to determine cytokines, growth factors, and other inflammatory components. To determine lung damage, total protein and lactate dehydrogenase levels in the BAL fluid can also be measured ${ }^{32,33}$. 
With the development of new diagnostic tools, the genomic and proteomic characterization of BAL components will be possible in the near future. The combination of expanding computational capabilities and high-throughput gene expression technologies will make it possible to define specific gene expression profiles for various disease states. Performing these techniques on BAL fluid can provide gene and protein expression patterns to identify the important molecules involved in the different phases of lung diseases.

The main limitation of data obtained from BAL fluid is the lack of comparability between different research trials ${ }^{3,9}$. There is a high degree of variability in the lavage technique and the subsequent processing of BAL fluid. To be able to compare each BAL trial, it is necessary to standardize the type of lavage fluid that is instilled, the site of instillation, and the fraction that is to be analyzed for cellular and non-cellular composition. There are significant differences in the number of lavage fractions between different trials, varying from one to 14 times ${ }^{34,35,36}$. This difference may have an impact on the estimated total cell numbers in the lungs. It is important to know which BAL fluid fraction contains the majority of cells. Song et al. showed that approximately $70 \%$ of the total number of cells were retrieved in fraction one to three ${ }^{22}$. However, other reports suggested that the second lavage contained more cells than the first one ${ }^{37,38}$. We can conclude from these studies that a lavage with just one fraction does not represent the whole lung, leading to misinterpretation of the results.

The noncellular composition of the BAL fluid contains valuable information on the health status of the lung ${ }^{33,39,40}$. Variations in the dilution of the BAL fluid contributes to the difference in the quantification of the soluble fraction and, consequently, to differences in the results between trials. Song et al. compared the protein and lactate dehydrogenase levels of each lavage fraction and concluded that the first lavage fraction contained two to three times more than the second fraction.

To retrieve a representative BAL sample for analysis, some technical considerations are crucial. One of them is to perform proper anesthetization. It is very important to check the foot reflex of the mouse to ensure terminal sedation. This is not only important for ethical reasons, but also because it is difficult to place and retain the catheter in the correct position if the mouse is not properly anesthetized.

A second important technical consideration is the position of the catheter in the trachea. When the catheter is inserted too deep, it can damage the lung structure. The distal end of the catheter should not reach the lungs during the BAL procedure. The catheter should also be stabilized and tied off with a cotton thread. If the catheter is not stabilized, the injected saline solution may flow upwards into the nasal cavity instead of down into the lungs. During injection and aspiration of the saline solution, it is important to hold the catheter steady.

The data obtained from the BAL fluid must represent the whole murine lung. Therefore, it is important to instill an adequate volume of saline buffer (i.e. $3 \mathrm{~mL}$, divided in 3 aliquots of $1 \mathrm{~mL}$ each). There is no linear relationship between the cell yield and the BAL fluid yield. It is important to collect the solution gently while massaging the thorax of the mouse. If shearing forces are too strong, the viability, function, and structure of cells within the airways and BAL fluid may be compromised. If the aspirated fluid is not visible in the syringe, carefully move the catheter deeper or higher in the trachea.

Special notice should be given to specific aspects of BAL processing and analysis. This will maximize the information retained from BAL samples. After BAL, the cells are in a nutrient-poor saline medium. It is therefore very important to process the samples within $1 \mathrm{~h}$ after BAL sampling. If prolonged storage is necessary, the use of a nutrient-supplemented medium is required.

To preserve cell viability, avoid tubes that promote cell adherence to the surface. Avoid centrifugation of cell suspensions at speeds that are likely to compromise cellular integrity or to prevent uniform resuspension of the retrieved BAL cells. BAL fluid containing cells should be centrifuged at $400 \mathrm{xg}$ and $4{ }^{\circ} \mathrm{C}$ for $7 \mathrm{~min}$. It is important to keep in mind that cell suspensions should be held at $4{ }^{\circ} \mathrm{C}$ during processing.

\section{Disclosures}

The authors have nothing to disclose.

\section{Acknowledgements}

L.V.H. is a research assistant at the Department of Biomedical Molecular Biology of Ghent University. E.R.J. is supported by UniVacFlu, grant number 607690. K.R. is supported by EC-FP7 project FLUNIVAC.

\section{References}

1. Stankunas, K. et al. Conditional protein alleles using knockin mice and a chemical inducer of dimerization. Mol Cell. 12 (6), 1615-1624, (2003).

2. Hunninghake, G. W., Gadek, J. E., Kawanami, O., Ferrans, V. J., \& Crystal, R. G. Inflammatory and immune processes in the human lung in health and disease: evaluation by bronchoalveolar lavage. Am J Pathol. 97 (1), 149-206 (1979).

3. Gee, J. B., \& Fick, R. B., Jr. Bronchoalveolar lavage. Thorax. 35 (1), 1-8 (1980).

4. Tornling, G. et al. Hyaluronic acid in bronchoalveolar lavage in rats exposed to quartz. Br J Ind Med. 44 (7), $443-445$ (1987).

5. Henderson, R. F. Use of bronchoalveolar lavage to detect respiratory tract toxicity of inhaled material. Exp Toxicol Pathol. $\mathbf{5 7}$ Suppl 1 155-159, (2005).

6. Morris, A. et al. Longitudinal analysis of the lung microbiota of cynomolgous macaques during long-term SHIV infection. Microbiome. 4 (1), 38 (2016).

7. Naessens, T. et al. GM-CSF treatment prevents respiratory syncytial virus-induced pulmonary exacerbation responses in postallergic mice by stimulating alveolar macrophage maturation. J Allergy Clin Immunol. 137 (3), 700-709 e709 (2016).

8. Chockalingam, A., Duraiswamy, R., \& Jagadeesan, M. Bronchoalveolar lavage cellular analyses in conjunction with high-resolution computed tomography imaging as a diagnostic intervention for patients with suspected interstitial lung disease. Lung India. 33 (3), $287-291$ (2016). 
9. Crystal, R. G., Reynolds, H. Y., \& Kalica, A. R. Bronchoalveolar lavage. The report of an international conference. Chest. 90 (1), $122-131$ (1986).

10. Baughman, R. P. The uncertainties of bronchoalveolar lavage. Eur Respir J. 10 (9), 1940-1942 (1997).

11. Singletary, M. L. et al. Modification of a common BAL technique to enhance sample diagnostic value. J Am Assoc Lab Anim Sci. 47 (5), $47-51$ (2008).

12. Angus, D. W., Baker, J. A., Mason, R., \& Martin, I. J. The potential influence of CO2, as an agent for euthanasia, on the pharmacokinetics of basic compounds in rodents. Drug Metab Dispos. 36 (2), 375-379 (2008).

13. Menon, V., Thomas, R., Ghale, A. R., Reinhard, C., \& Pruszak, J. Flow cytometry protocols for surface and intracellular antigen analyses of neural cell types. J Vis Exp. (94) (2014).

14. Inglis, H., Norris, P., \& Danesh, A. Techniques for the analysis of extracellular vesicles using flow cytometry. J Vis Exp. (97) (2015).

15. Rubio-Navarro, A. et al. Phenotypic Characterization of Macrophages from Rat Kidney by Flow Cytometry. J Vis Exp. (116) (2016).

16. Butcher, M. J., Herre, M., Ley, K., \& Galkina, E. Flow cytometry analysis of immune cells within murine aortas. J Vis Exp. (53) (2011).

17. Noto, A., Ngauv, P., \& Trautmann, L. Cell-based flow cytometry assay to measure cytotoxic activity. J Vis Exp. (82) e51105 (2013).

18. Adan, A., Alizada, G., Kiraz, Y., Baran, Y., \& Nalbant, A. Flow cytometry: basic principles and applications. Crit Rev Biotechnol. 1-14 (2016).

19. Database, J. S. E. The ELISA method. J Vis Exp. (2016).

20. Gallagher, S., \& Chakavarti, D. Immunoblot analysis. J Vis Exp. (16) (2008).

21. Wunderlich, M. L., Dodge, M. E., Dhawan, R. K., \& Shek, W. R. Multiplexed fluorometric immunoassay testing methodology and troubleshooting. J Vis Exp. (58) (2011).

22. Song, J. A. et al. Standardization of bronchoalveolar lavage method based on suction frequency number and lavage fraction number using rats. Toxicol Res. 26 (3), 203-208 (2010).

23. Seliger, C. et al. A rapid high-precision flow cytometry based technique for total white blood cell counting in chickens. Vet Immunol Immunopathol. 145 (1-2), 86-99 (2012).

24. Daniele, R. P., Elias, J. A., Epstein, P. E., \& Rossman, M. D. Bronchoalveolar lavage: role in the pathogenesis, diagnosis, and management of interstitial lung disease. Ann Intern Med. 102 (1), 93-108 (1985).

25. Delayre-Orthez, C., Becker, J., de Blay, F., Frossard, N., \& Pons, F. Exposure to endotoxins during sensitization prevents further endotoxininduced exacerbation of airway inflammation in a mouse model of allergic asthma. Int Arch Allergy Immunol. 138 (4), 298-304 (2005).

26. Delayre-Orthez, C. et al. PPARalpha downregulates airway inflammation induced by lipopolysaccharide in the mouse. Respir Res. 691 (2005).

27. Delayre-Orthez, C., de Blay, F., Frossard, N., \& Pons, F. Dose-dependent effects of endotoxins on allergen sensitization and challenge in the mouse. Clin Exp Allergy. 34 (11), 1789-1795 (2004).

28. Hachet-Haas, M. et al. Small neutralizing molecules to inhibit actions of the chemokine CXCL12. J Biol Chem. 283 (34), 23189-23199 (2008).

29. Ble, F. X. et al. Activation of the lung S1P(1) receptor reduces allergen-induced plasma leakage in mice. Br J Pharmacol. 158 (5), $1295-1301$ (2009).

30. Ble, F. X. et al. Allergen-induced lung inflammation in actively sensitized mice assessed with MR imaging. Radiology. 248 (3), $834-843$ (2008).

31. Reber, L. L. et al. A dissociated glucocorticoid receptor modulator reduces airway hyperresponsiveness and inflammation in a mouse model of asthma. J Immunol. 188 (7), 3478-3487 (2012).

32. Drent, M., Cobben, N. A., Henderson, R. F., Wouters, E. F., \& van Dieijen-Visser, M. Usefulness of lactate dehydrogenase and its isoenzymes as indicators of lung damage or inflammation. Eur Respir J. 9 (8), 1736-1742 (1996).

33. Henderson, R. F. Use of bronchoalveolar lavage to detect lung damage. Environ Health Perspect. 56 115-129 (1984).

34. Forget, G. et al. An adherent cell perifusion technique to study the overall and sequential response of rat alveolar macrophages to toxic substances. Environ Health Perspect. 51 131-140 (1983).

35. Sung, J. H. et al. Recovery from welding-fume-exposure-induced lung fibrosis and pulmonary function changes in sprague dawley rats Toxicol Sci. 82 (2), 608-613 (2004).

36. Majetschak, M., Sorell, L. T., Patricelli, T., Seitz, D. H., \& Knoferl, M. W. Detection and possible role of proteasomes in the bronchoalveolar space of the injured lung. Physiol Res. 58 (3), 363-372 (2009).

37. Rehn, B., Bruch, J., Zou, T., \& Hobusch, G. Recovery of rat alveolar macrophages by bronchoalveolar lavage under normal and activated conditions. Environ Health Perspect. 97 11-16 (1992).

38. Kelly, C. A., Ward, C., Stenton, S. C., Hendrick, D. J., \& Walters, E. H. Assessment of pulmonary macrophage and neutrophil function in sequential bronchoalveolar lavage aspirates in sarcoidosis. Thorax. 43 (10), 787-791 (1988).

39. Eklund, A., Tornling, G., Blaschke, E., \& Curstedt, T. Extracellular matrix components in bronchoalveolar lavage fluid in quartz exposed rats. Br J Ind Med. 48 (11), 776-782 (1991).

40. Olsen, G. N., Harris, J. O., Castle, J. R., Waldman, R. H., \& Karmgard, H. J. Alpha-1-antitrypsin content in the serum, alveolar macrophages, and alveolar lavage fluid of smoking and nonsmoking normal subjects. J Clin Invest. 55 (2), 427-430 (1975). 